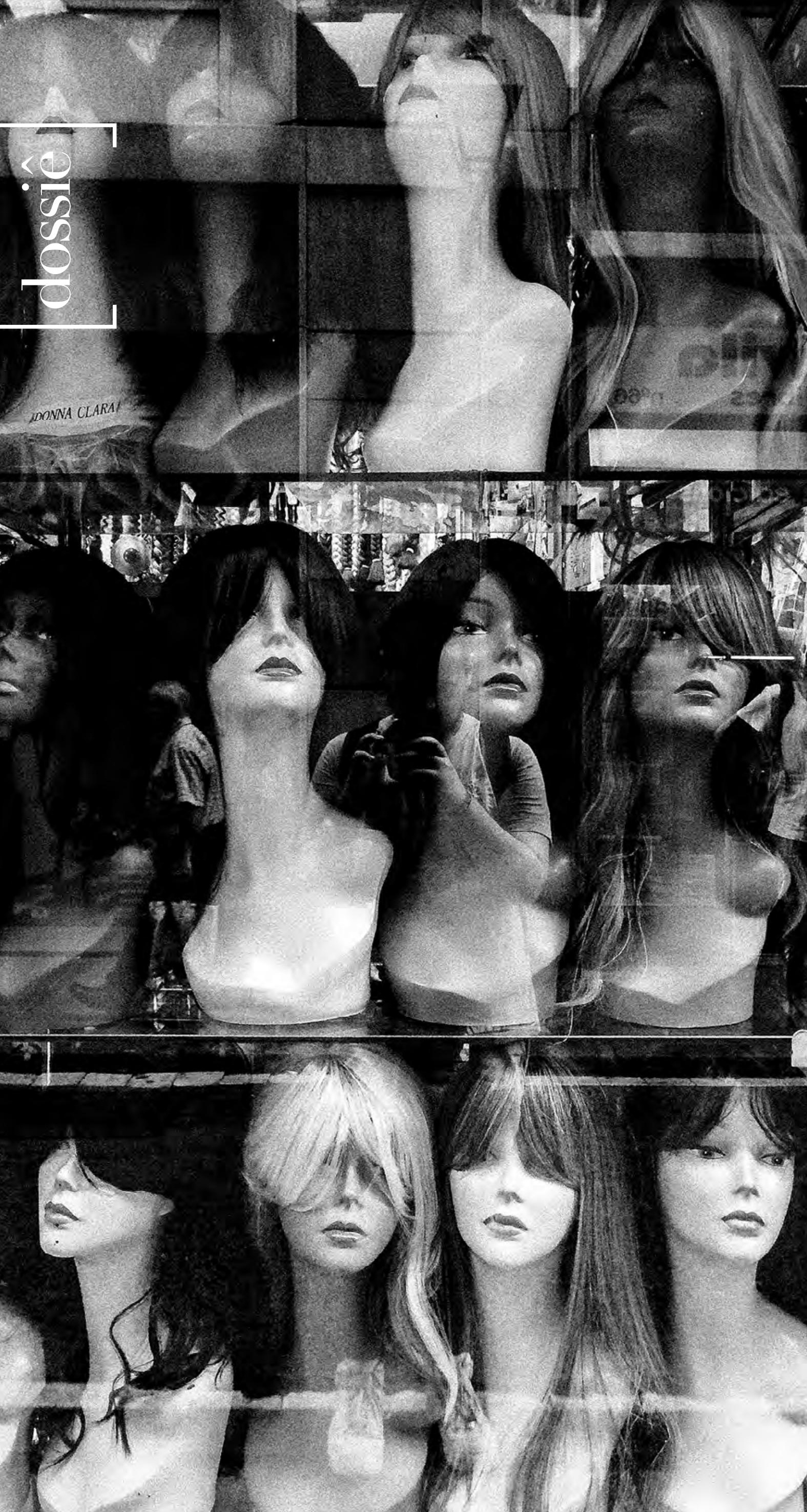




\section{Cultura de Moda na América Latina}

Cultura de moda na América Latina! É com grande satisfação que publicamos este dossiê que, há aproximadamente um ano, teve início com a chamada de artigos e colaborações para este número. A pretensão de fazer emergir pesquisas que problematizassem a moda no nosso continente era uma ideia que vinha sendo pensada a partir de algumas descobertas importantes até então desconectadas.

0 primeiro impulso resultou de uma pesquisa realizada na Universidade Anhembi Morumbi, em São Paulo. Em fevereiro de 2016, foram concedidas três bolsas de iniciação científica para alunos que realizariam uma pesquisa qualitativa e quantitativa sobre a oferta de ensino superior em Moda em algumas regiões geográficas específicas, com o objetivo de mapear o ensino superior de Moda. Os resultados finais, apurados em maio de 2017, indicaram o funcionamento de cem cursos superiores de Moda nos paises hispano-americanos e 214 somente no Brasil. Todos esses cursos e instituições tanto produzem quanto requerem conhecimento que faça cada vez mais sentido diante das questões locais, motivo primeiro para a organização deste dossiê.

A segunda motivação ou ideia decorreu da percepção cada vez mais clara da dificuldade de fazer com que pesquisas que partem da América Latina tenham alcance global. Tanto os eventos internacionais quanto as publicações das grandes editoras científicas dificilmente possuem representantes da América Latina publicando ou apresentando suas pesquisas. Isso não quer dizer que eles não existam nem que sejam raros, mas, certamente, não têm nem a presença nem a relevância proporcionais e merecidas da nossa produção científica. Barreiras linguísticas e geográficas contribuem para que a cultura de moda latino-americana seja pouco ou mal conhecida internacionalmente e, por causa disso, este dossiê também tem a missão de promover essas questões e pesquisas para um grupo maior.

Por fim, mas sem esgotar as motivações, este dossiê ainda deseja estimular a reflexão sobre a cultura de moda em nossos países. É claro que qualquer pesquisa sobre moda que parta de um objeto ou de um problema que surge em nossa região é certamente latino-americana, mas a ideia vai um pouco mais além. Seria a de (re)considerar, ao menos eventualmente, o papel que a dimensão geográfica ocupa nas certezas e incertezas de nossas pesquisas sobre moda. Aspira-se que essa reflexão ocupe também o território da criação e da produção de moda.

Os artigos recebidos, e que teremos a sorte e o prazer de lê-los a seguir, respondem às descobertas previamente mencionadas. Todos eles refletem as 
questões anteriormente apontadas, o que indica a necessidade cada vez maior de se discutir a moda dentro e a partir do contexto latino-americano.

0 primeiro artigo do dossiê é uma importante contribuição de Erynn Casanova, professora da Universidade de Cincinnati, nos Estados Unidos. Beauty ideology in Latin America desenvolve-se a partir da formação e do estabelecimento dos padrões de beleza na América Latina que são utilizados por diferentes indústrias culturais, da televisão aos cosméticos passando pela indústria do vestuário.

A beleza latino-americana tanto é um tema relevante que o segundo artigo deste dossiê parte dos desfiles de Miss Universo para tratar da elaboração/criação dos trajes nacionais das misses da Colômbia, ou seja, considera a beleza como símbolo da nação. No artigo The land of the most beautiful natural resources: Miss Universo: representaciones de El Dorado y el traje típico colombiano, Andrés Leonardo Caballero Piza mostra como elementos considerados representativos da expressão da cultura colombiana, que se alicerçam nos recursos naturais da terra, tornam-se trajes que identificam a nação. $A$ beleza da mulher latina é potencializada por técnicas e materialidades tidas como originais da Colômbia que chegam até nós pelos livros de história, pelos mitos e por outros recursos simbólicos.

No mesmo caminho dos trajes nacionais, Fuviane Galdino Moreira traz uma pesquisa inédita sobre as vestes das padroeiras no artigo $A$ beleza do divino: vestes como ornamento na imaginária cristã. A partir do estudo das vestes de duas padroeiras latino-americanas, a autora discute alguns costumes vestimentares das imagens religiosas de modo a apontar particularidades que se manifestam de acordo com a origem das imagens. 0 artigo demonstra também a necessidade de tomar essas imagens como objetos de estudo dentro do campo dos têxteis.

Rebecca Devaney dá sequência à reflexão sobre a materialidade têxtil na América Latina com o artigo A stitch in time: embroidered textiles from Mexico. 0 texto é resultado de pesquisa e prática in loco durante uma longa jornada no México, a qual colocou a autora em contato com diferentes técnicas, estilos, práticas, processos etc. do artesanato têxtil mexicano. A ênfase do artigo está nas atividades de aprendizagem e transmissão das competências técnicas e estéticas do bordado dentro das comunidades visitadas e de sua transformação em objetos representativos da cultura mexicana.

0 dossiê termina com o artigo de Poliene Bicalho cobrindo uma imperdoável lacuna nos estudos sobre a cultura de moda brasileira. A autora contribui com este dossiê com o artigo Se pinta e se veste: a segunda pele indígena e esclarece alguns elementos fundamentais para melhor caracterizar e compreender a segunda pele indígena dentro dos estudos da moda no Brasil que se dirigem a essa questão. A urgência da discussão desse tema é inegável diante da dificuldade que os pesquisadores do campo da Moda enfrentam ao tratar da relação do indígena com a ornamentação corporal. Não se deve esquecer de que essa é uma particularidade que caracteriza o Brasil e toda a América 
Latina e, até onde temos visto, a presença de culturas vestimentares diferentes da europeia (especificamente as indigenas) tornaram-se temas complexos e pouco presentes nos estudos mais disseminados.

Na seção de resenhas, Martha Sandoval colaborou com o texto Investigaciones hispanas de moda e indumentaria: avances metodológicos, generadores de conocimiento y nuevas herramientas, produzido a partir de sua participação no I Coloquio de Investigadores de Textil y Moda, organizado no museu têxtil de Terrassa (Barcelona), em novembro de 2017. Seu olhar focou a questão latino-americana e, como destacou a autora, a dificuldade de inserir nos debates espanhóis a participação de temas ou problemas dos paises hispano-americanos. Sua análise comprova a necessidade de globalizar nossas pesquisas.

A princípio, qualquer estudo que se detivesse sobre um objeto ou uma questão proveniente do continente latino-americano poderia ser considerado parte deste dossiê. Contudo, o objetivo dessa chamada de trabalhos foi reunir artigos que assumissem um olhar geográfico, isto é, que mostrassem o impacto da dinâmica econômica, social e cultural da região sobre a cultura da moda aqui experienciada. Com isso, não houve a intenção de isolar as questões latino-americanas das de outras regiões: ao contrário, procura-se mostrar como esses temas fazem parte de uma cultura de moda global e a necessidade de entrelaçá-los às pesquisas científicas mais consolidadas.

9 ] Antes de finalizar esta apresentação, devo agradecer o convite para organizá-la, bem como a todos os pesquisadores que dedicaram seu tempo à leitura dos artigos que agora compõem o dossiê. Tanto autores quanto avaliadores de diferentes nacionalidades e idiomas dedicaram seu tempo e seu conhecimento para este projeto.

Boa leitura!

LUZ NEIRA GARCÍA

Pesquisadora independente. E-mail: luz.neira.garcia@outlook.com 